\title{
Fire in the woods or fire in the boiler: implementing rural district heating to reduce wildfire risks in the forest-urban interface
}

Juan A. Blanco ${ }^{a, 1}$, David Dubois ${ }^{b}$, Dale Littlejohn ${ }^{c}$, David N. Flanders ${ }^{d}$, Peter Robinson ${ }^{c}$, Molly Moshofsky ${ }^{a}$, Clive Welham ${ }^{a}$

${ }^{a}$ Dep. Forest Sciences, University of British Columbia, 2424 Main Mall, Vancouver, BC, V6T1Z4, Canada

${ }^{\mathrm{b}}$ Wood Waste to Rural Heat Project, c/o Community Futures East Kootenay, 110A Slater Road NW, Cranbrook, BC, V1C 5C8, Canada

${ }^{c}$ Community Energy Association, 3324 - 2260 West Mall, University of British Columbia, Vancouver, BC, V6T1Z4, Canada

${ }^{d}$ Collaborative for Advances Landscape Planning, Centre for Interactive Research \& Sustainability, University of British Columbia, 2321 - 2260 West Mall, Vancouver, BC, V6T1Z4, Canada

${ }^{1}$ Contact author \& Author present address:

Dep. Ciencias del Medio Natural, Universidad Pública de Navarra

Campus de Arrosadia, Pamplona, Navarra, 31006, Spain

Tel: +34948169859

Fax: +34 948168930

E-mail: juan.blanco@unavarra.es

Manuscript presented at the conference "CSChE/IChemE Sustainability Symposium, Vancouver 2012" 


\section{ABSTRACT}

Many rural communities in British Columbia (western Canada) are at risk from wildfire. This risk will increase over time as a result of climate change because of higher average temperatures, longer growing seasons, and more intense droughts. On the other hand, these communities are also faced with rising fuel costs and a growing demand for heat as suburban population increases. The fact these communities are surrounded by forests presents an opportunity to combine community wildfire risk abatement with bioenergy development. Additional co-benefits include: 1) reduced community energy expenditures; 2) the creation of local jobs; 3) climate change mitigation; and 3) increased community energy security. Here, we present results from three pilot rural communities (Burns Lake, Invermere, and Sicamous, British Columbia) designed to evaluate the feasibility of wildfire risk abatement in conjunction with bioenergy production. Maps were created showing each community's forest-urban interface area with quantified estimates of its sustainable woody biomass resource potential under different management scenarios while monitoring ecosystem and soil health. The results and experience gained through this work has been synthesized in a calculator tool to help other communities make their own screening-level assessments. This calculator is a freely available on-line tool: FIRST Heat.

Keywords: woody biomass, ecological model, sustainable energy, green economy, sustainable forest management, climate change mitigation, FIRST Heat. 


\section{INTRODUCTION}

Since Canada's census of 1981, there has been a clear trend for rural suburban spaces to grow in population at a rate higher than for city centers (Hirsch and Funglem, 2006). In British Columbia (BC), western Canada, the area of the forest-urban interface has been steadily increasing over the last few years. The forest, parkland, and agricultural landscapes of $B C$ are now scattered with buildings and infrastructure vulnerable to wildfire (Partners in Protection, 2003). As a consequence, the forest-urban interface is a region "on the edge", vulnerable to damage and evacuation orders as wildfires strike.

All forests in interior BC are subject to wildfire. Although these forest ecosystems are naturally resilient to fire, they are actually adapted to a specific fire regime, a combination of fire frequency, intensity, and severity (Johnson et al., 2002). However, external factors are changing natural fire regimes. For example, excessive fire suppression (Keeley et al., 1999) or tree mortality causes an accumulation of fuel and therefore increases fire occurrence and/or intensity (Jolly et al., 2012). Another example is the increase in fire frequency from direct anthropogenic sources (escaped fires, sparks, etc.) that occurs when more people live in the forest-urban interface. Direct links between climate change and more fires have also been reported (Westerling et al., 2006), and predicted for western North America (Hirsch and Fuglem, 2006; de Groot et al., 2012; Nitschke and Innes, 2013). Due to this increasing area under wildfire risk, communities around BC (especially in the interior) are implementing preventive forest management to reduce wildfire risk. These activities are generating woody biomass ${ }^{1}$ from the reduction in stand density. Until now, this woody biomass has been removed from site and then burned in piles, so it will not fuel future wildfires.

Rural communities incur fuel prices more expensive than in cities because fossil fuels have to be transported from the main population centers. For example, weekly retail furnace oil prices per litre in Prince George (BC) have been 6.8 cents higher on average than prices in Vancouver in the 2005-2014 decade (Natural Resources Canada 2015). Under current residential prices, propane is often at least twice as expensive as wood pellets (the most expensive form of woody biomass) and heating oil is even more expensive (Table 1). In addition, inflation adjusted fuel prices in Canada have been growing for all oil- and gasrelated products (with volatility due to international events) (National Energy Board 2011). The long-term trend for fossil fuel prices is for them to rise, putting pressure on local economies. Therefore, there are economic as well as environmental reasons to increase the use of woody biomass generated from the management of the forest-urban interface as a source of energy and thereby reduce the use of fossil fuels in these communities.

\footnotetext{
${ }^{1}$ Defined as the trees and woody plants, including limbs, tops, needles, leaves, and other woody parts, grown in a forest, woodland, or rangeland environment, that are the by-products of forest management (USFS 2008).
} 
It is estimated that sustainable forestry methods in BC could produce enough woody

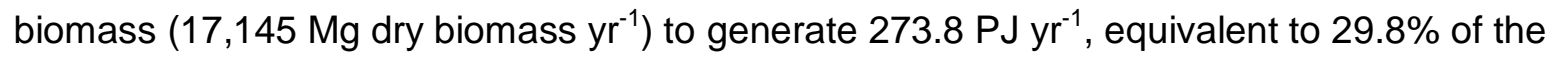
province's energy demand from fossil fuels. This estimate would be larger if the timber from trees killed by the mountain pine beetle outbreak were used, reaching a total of $28,100 \mathrm{Mg}$ dry biomass $\mathrm{yr}^{-1}$, (450 PJ $\left.\mathrm{yr}^{-1}\right)$ or $49.0 \%$ of BD's energy demand from fossil fuels (ENVINT Consulting, 2011). Although these are striking figures, BC's biomass potential is far from being fully utilised. Challenges include ensuring a stable long-term supply of biomass at a fixed price and quality, accessibility to biomass material, fluctuations in transportation costs, not clear increase in economic efficiency as the heating plant increases in size, previous investments on other energies that still need to be amortized, and bias against biomass due to public perception of potential air quality issues (Renney 2012).

The ecological context of woody biomass is an important consideration, however, because from the perspective of a forest ecosystem, there is no "waste" biomass. All forest residues are part of long-term nutrient dynamics. Research shows that removing woody biomass, traditionally left in BC's forests after harvesting, could have negative impacts on fauna (Sullivan et al., 2011) and flora (Blanco, 2012). A final environmental factor to be considered when using woody biomass as a source for district heating ${ }^{2}$ fuel is the reduction of carbon dioxide emissions. Studies suggest that the most cost-effective solutions for reducing carbon emissions from buildings involve minimizing energy usage, maximizing efficiency, and fuel switching to lower carbon fuels (Flanders et al., 2009). Fuel switching will ultimately play a larger role than energy efficiency in reducing greenhouse gasses emissions (Simpson et al., 2007). For example, in interior communities in BC, space and water heating are among the major contributors to greenhouse gas emissions (Sheltair, 2007; Green Heat Initiative, 2010). By focusing on alternative, low-carbon heat sources, these communities can reduce their dependence on fossil fuels for heating.

The challenge for planners and local managers in rural BC is how to keep their communities safe and attractive for locals, newcomers, and visitors, while reducing safety risks, energy costs, and their carbon footprint. Together, these issues make for a complex picture as communities struggle to realise the potential of their forest-urban interface areas. A joint project involving the University of British Columbia, Community Energy Association and Wood Waste to Rural Heat Project has developed a tool called FIRST Heat. This tool is a

\footnotetext{
${ }^{2}$ District heating is a system in which hot water (steam in old systems) is distributed from central stations to buildings and industries in a densely occupied area (a district, a city or an industrialized area). The insulated twopipe network functions like a water-based central heating system in a building. The central heat sources can be waste-heat recovery at industrial processes, waste-incineration plants, cogeneration power plants or standalone boilers burning fossil fuels or biomass (IPCC 2011).
} 
calculator that will help local authorities, planners and forest managers evaluate whether they could pursue a district energy systems project that combines wildfire risk control and bioenergy production, and if so which wildfire control regimes may be ecologically sustainable. The objective of this paper is to describe the development and operation of this calculator.

\section{MATERIALS AND METHODS}

The calculator "Fire Interface Rural Screening Tool for Heating" (FIRST Heat) is a Microsoft Excel® spreadsheet in which users can select different options from drop-down menus and input parameter values specific to their communities (or select among the default values). It is freely available at the Community Energy Association website (http://communityenergy.bc.ca/?dlm_download_category=heating), and as a Supplementary file to this manuscript. This tool has been developed for three pilot communities in BC. It combines estimation of future tree growth from an ecological model, engineering calculations describing district heating systems, and economic features estimating the associated financial costs and benefits (Figure 2).

\subsection{Study areas}

Pilot communities were selected based on their small population size, no existing district energy systems, and location. The latter translates into difficult access to the natural gas grid, surrounded by forests prone to wildfires, and representing different biogeoclimatic zones (Pojar et al., 1987) to provide a diversity of forest types in the study (Figure 1). These communities are:

- Burns Lake (Northern BC), in the interior plateau within the sub-boreal spruce biogeoclimatic zone (SBS). Sub-boreal climate (cold winters, short summers) create a landscape where hybrid Engelmann-white spruce (Picea engelmannii x glauca) and subalpine fir (Abies lasiocarpa) are the dominant trees; extensive stands of lodgepole pine (Pinus contorta) occur in the dryer portions of the zone due to numerous past fires. Wetlands are abundant, dotting the landscape in poorly drained areas. The City of Burns Lake is connected to the natural gas grid but with a gas price $50 \%$ higher than what is typical in BC.

- Sicamous (Shuswap Valley), interior cedar-hemlock biogeoclimatic zone (ICH). Continental climate (cold winters, warm and dry summers) defines the area, where Western hemlock (Tsuga heterophylla) and western redcedar (Thuja plicata) are characteristic species but spruce (Engelmann-white hybrids), and subalpine fir are not unusual. Douglas-fir (Pseudotsuga menziesii) and lodgepole pine are generally found on drier sites. The city of Sicamous is not connected to the gas grid. 
- Invermere (Kootenay mountains), in the montane spruce biogeoclimatic zone (MS). Continental-alpine climate is predominant, with Engelmann and hybrid spruce, and varying amounts of subalpine fir as characteristic tree species. However, due to past wildfires successional forests of lodgepole pine, Douglas-fir and trembling aspen (Populus tremuloides) are common. Invermere it is not connected to the gas grid.

Personal interviews and a review of official documents were carried out on-site in each community to gather information on local wildfire protection plans, management recommendations, ecological surveys, and other related information. For each zone, GIS maps of the surrounding area in a 25-km radius were generated, using data from BC's Vegetation Resources Inventory (available at: http://www.for.gov.bc.ca/hts/vri/). Forest stands (GIS polygons) in each map were classified into different forest types depending on their biogeoclimatic zone, dominant tree species, density and tree age (see list of stand types in Table S3 in the Supplementary material).

\subsection{Forest biomass modeling}

\subsubsection{Wildfire risk management scenarios}

The information provided by the communities, combined with FireSmart guidelines (Partners in Protection, 2003) was used to design three different management regimes. They represent the trade-offs faced by many communities between carrying out intensive but costly forestry operations to maintain wildfire risk at minimum, and the cost of such operations.

- Intense management to keep wildfire risk at minimum: post-thinning conifer target density was 121 trees ha-1 (6 meters between crowns) in Burns Lake and Sicamous, 65 trees ha ${ }^{-1}$ (11 meters between crowns) in Invermere, branches pruned up to $3 \mathrm{~m}$, undergrowth control operations carried out every 5 years, removing all new trees, understory and downed coarse woody debris with diameter $>10 \mathrm{~cm}$.

- Moderate management: post-thinning target conifer density of 121 trees ha $^{-1}$ (6 meters between crowns), branches pruned up to $3 \mathrm{~m}$, undergrowth control operations every 10 years, removing all new trees and understory, and downed coarse woody debris with diameter $>10 \mathrm{~cm}$.

- Minimum management to keep wildfire risk inside safety standards: post-thinning conifer target density of 286 trees ha $^{-1}$ ( 3 meters between crowns), branches pruned up to $2.5 \mathrm{~m}$, undergrowth control operations every 10 years, removing all new trees and understory, and downed coarse woody debris with diameter $>10 \mathrm{~cm}$.

In all management regimes, broadleaf trees were left on site without thinning or harvesting, to maintain their effect as wildfire barriers (Partners in Protection, 2003).

\subsubsection{The ecological forest model FORECAST}


FORECAST is a management-oriented, deterministic, stand-level forest growth and ecosystem dynamics simulator that operates at annual time steps. A detailed description is provided in the Supplementary material, as well as in previous publications (Kimmins et al., $1999,2010)$, and therefore only a summary of the main driving function to calculate tree growth is provided here. The model uses a mass balance approach to estimate how nutrients circulate in a forest ecosystem, and how their availability limits tree growth together with available light in the canopy (Figure 3, Figure S1). FORECAST has three application stages:

1) assembling calibration data and generating historical rates of key ecosystem processes;

2) model initialization by establishing the ecosystem condition for the beginning of a simulation run; and 3) simulation of tree and plant growth.

Model calibration: For each forest type, calibration data are assembled that describe the accumulation of biomass (above and below-ground components) in trees and minor vegetation for three chronosequences of stands, each one developed on homogeneous conditions, representing three different nutritional qualities. Tree biomass and stand selfthinning rate data are often generated from height, $\mathrm{DBH}$ and stand density output of traditional growth and yield models in conjunction with species-specific component biomass allometric equations. To calibrate the nutritional aspects of the model, data describing the concentration of nutrients in the various biomass components are required. FORECAST also requires data on the degree of shading produced by different quantities of foliage and the photosynthetic response of foliage to different light levels. A comparable but simpler set of data for minor vegetation must be provided if the user wishes to represent this ecosystem component. Lastly, data describing the rates of decomposition of various litter types and soil organic matter are required for the model to simulate nutrient cycling.

The FORECAST datasets used for this project were based on existing calibration datasets assembled as part of a project funded by the Canadian Foundation for Innovation. In all cases calibration data (biomass accumulation rates, top height, diameter at breast height, and stand density) were derived from regional growth and yield tables in combination with species-specific allometric biomass equations. Other calibration data were derived from literature sources: nitrogen concentrations in biomass components (Kimmins et al., 1979; Peterson and Peterson, 1992; Wang et al., 1996), decomposition rates (Prescott et al., 2000a, 2000b; Camrie et al., 2002), litterfall rates (Kimmins et al., 1979; Peterson, 1988; Li et al., 2003), light transmission (Messier et al., 1998; Leifers et al., 2002; Comeau and Heineman, 2003), light-limited growth rates (Mailly and Kimmins, 1997; Leifers et al., 2002; Claveau et al., 2002). FORECAST has been used in previous studies for an examination of soil productivity (e.g. Morris et al., 1997; Seely, 2005; Seely et al., 2010; Blanco, 2012), and it has been evaluated against field data for growth, yield, ecophysiological and soil variables 
for several BC's forest types (see detailed model evaluation in the Supplementary material; Blanco et al., 2007; Seely et al., 2008, 2010). Calibration values for the most important parameters can be found in those studies are not repeated here.

Model initialization: The second aspect of calibration requires running the model in "set-up" mode to establish initial site conditions. The detailed representation of many different litter types and soil organic matter conditions makes it impractical to measure initial litter and soil conditions directly in the field; consequently, the model is used to generate starting conditions, simulating the historical fire regimes in a steady-state condition (for a broader discussion on this topic see, for example, Seely et al., 2002; Welham et al., 2002). Based on data on fire regimes for each BEC, the initial conditions were created for each ecosystem type using the parameters shown in Table S4 (Supplementary material).

Simulation of tree growth: The FORECAST model was designed to accommodate a wide variety of harvesting and silvicultural systems in order to compare and contrast their effect on forest productivity, stand dynamics and a series of biophysical indicators of non-timber values. Projection of stand growth and ecosystem dynamics is based upon a representation of the rates of key ecological processes regulating the availability of, and competition for, light and nutrient resources. The rates of these processes are calculated from a combination of historical bioassay data (biomass accumulation in component pools, stand density, etc.) and measures of certain ecosystem variables (decomposition rates, photosynthetic saturation curves, for example) by relating 'biologically active' biomass components (foliage and small roots) with calculations of nutrient uptake, the capture of light energy, and net primary production. Using this approach, the model generates a suite of growth properties for each tree and plant species to be represented. These growth properties are subsequently used to model growth as a function of resource availability and competition. They include (but are not limited to): 1) photosynthetic efficiency per unit foliage biomass based on relationships between foliage biomass, simulated self-shading, and net primary productivity after accounting for litterfall and mortality; 2) Nutrient uptake requirements based on rates of biomass accumulation and literature- or field-based measures of nutrient concentrations in different biomass components on different site qualities; and 3) light-related measures of tree and branch mortality derived from stand density input data in combination with simulated light profiles. Light levels at which foliage and tree mortality occur are estimated for each species. FORECAST performs many calculations at the stand level but it includes a submodel that disaggregates stand-level productivity into the growth of individual stems with user-inputted information on stem size distributions at different stand ages. Top height and DBH are calculated for each stem and used in a taper function to calculate total and individual gross and merchantable volumes. 
Three different forest age scenarios were simulated for each forest type: young forest (average stand age between 0 to 80 years), mature forest (average stand age between 80 150 years), and old-growth (average stand age 150 or older). For each forest type, management operations were simulated to start at the average stand age for each age scenario and lasted for 50 years. The resulting 50-year trends of tree, understory, and forest soil biomasses for each simulation were linked to each polygon type in a GIS ESRI ArcGIS. From the map, totals of biomass production were calculated for three different levels of land available for forest management: 1) All forest stands within $25 \mathrm{~km}$ of each community; 2) All forest stands in $25 \mathrm{~km}$ actually available for long-term management (excluding reserve zones of any kind); and 3) All forest stands in $25 \mathrm{~km}$ at high risk to wildfire and also available for long-term management. The final product of the modelling and biomass mapping was a library with 81 different values for all the combinations of ecological zone, management regime, dominant forest age, and land under wildfire risk management.

Although for many interior BC communities, the Mountain Pine Beetle (MPB) epidemic is a catalyst for considering biomass heating projects and although MPB wood can be used in these systems, the FIRST Heat Tool is a long term (50 year) planning tool that extends past the projected time frame for the MPB. Forest biomass estimations and forest growth simulations with FORECAST, therefore, did not account for MPB dynamics or wood supply.

\subsection{District heating modelling}

Using the three study cases communities as examples, the user selects a combination of the four main determinants (dominant biogeoclimatic zone, dominant forest age, intensity of fireprevention management, and area under management) that most closely describe the target community in the FIRST Heat tool interface (Figure 4). Then, the area that will be under management is inputted, which will work as a multiplier of the woody biomass selected from the library (calculated as the total of standing tree and understory biomass plus downed coarse woody debris removed during fire control operations). These data are sufficient to provide a value for woody biomass production at the community level for two different periods: the initial density control operations (years 1 to 10), and the regrowth control operations (years 11 to 50 ). The operational life of the system is estimated in 25 years, although with proper maintenance it could reach up to 50 years. This period is larger than the 10 years of the density control operations, and therefore the regrowth control operation should be the one feeding the boiler during the rest of the operative life of the system. As a consequence, the viability of the district heating system is calculated for the lowest woody biomass production time, the regrowth control period (Table 2). 
The user also has to provide input values (or accept the default values already implemented) for parameters defining the following categories:

- Energy in forest biomass: woody biomass losses in forest operations, energy content, tree species, moisture content.

- District heating system analysis: operational hours, plant and system efficiencies, building costs, boiler area, pipe grid length, trenching and pipe costs, years of operation.

- Life cycle analysis: operational life of boilers and piping, staff for operations, maintenance costs, fuel prices.

- Green gas emissions analysis: emission factors of tonnes of $\mathrm{CO}_{2}$ per $\mathrm{GJ}$ of energy used in the community.

- Community energy use: energy sources used and total energy use, total population growth.

With these data the tool calculates the heating energy potentially available for each community. All the engineering equations implemented in the tool are open source and can be accessed in the tool file (Supplementary material) and thus are not repeated here. The district heating system simulated in the FIRST Heat tool is assumed to use the best available proven technology with emissions approaching natural gas (for example, typical combustion systems with flue gas cleaning). It also assumes that there is a single heat plant designed to supply an average of $80-90 \%$ of total heat demand. Other fuels are used to supply heat during the rest of the time (heat demand in peak periods).

\subsection{Financial modelling}

To calculate the production costs per energy or per mass unit of woody biomass, the IPCC suggests the use of the Levelised Cost of Energy (LCOE) method, a technique based on net present value (IPCC, 2011). In the LCOE method (Equations 1-5), costs are used in the appraisal of power generation investments, where the outputs are quantifiable (MWh generated during the lifetime of the investment). The levelised costs is the unique break-even cost price where discounted revenues (calculates as price by quantities) are equal to the discounted net expenses. We used an adaptation of Darling et al. (2011)'s method:

Annuity factor $=\frac{\left((1+p)^{n}\right)-1}{p(1+p)^{n}}$

Annual Energy Production $=$ annual biomass input $\times$ system efficiency

Operation \& Management Costs = biomass fuel costs + energy peaking costs (3)

Initial costs $=$ Building costs + Boiler cost + Grid cost

$L C O E=\frac{\text { Initial costs }}{\text { annuity factor } \times A E P}+\frac{O M C}{A E P}$ 
Where $n$ : number of years of system utilization, and $\mathrm{p}$ : discount rate. LCOE expresses the lifecycle cost of energy from a system per unit of energy delivered. It takes into account the capital cost, discount rate, expected years of system utilisation, annual energy production, and all ongoing operation and maintenance costs. The LCOE is an abstraction from reality and is used as a ranking or benchmarking toll to assess the cost-effectiveness of different energy generation technologies (Branker et al., 2011).Therefore, this method allows the cost of energy from different systems to be directly compared. However, this method usually does not include risks and different actual financing methods available for the different technologies (Darling et al., 2011). As a benchmarking tool, it is sensitive to the assumptions made, especially when extrapolated several years into the future (Sevilgen et al., 2005; Darling et al., 2011). LCOE is a static measure that looks at a snapshot in deriving the price for generated energy, while true energy markets are dynamic (Branker et al., 2011). However, we consider that it is also a very useful index for its inclusion in a first stage screening tool such as FIRST Heat, as it can help to make an initial decision if the economics of using the residue from wildfire control risk operations are favourable or not, before doing more detailed analyses.

The FIRST Heat tool then provides a value of dollars per GJ when using biomass as the main energy source, and using other fuels during periods of peak demand (Table 2). To avoid increasing complexity of our results while focusing on the suitability of our new tool we set up the average woody biomass extraction costs at $\$ 50-\$ 75$ per $\mathrm{Mg}$ (tonne) of dry matter for all the study cases (average values for low/medium intensity and high-intensity forest operations from MacDonald 2006). We recognize that woody biomass extraction costs are highly variable depending on local conditions (tree species, site quality, forest age, accessibility, available labour, equipment used and time of the year when wildfire risk operations are carried out, among others), and therefore the FIRST Heat tool has the option to change such value. Advanced users are encouraged to do so.

\section{RESULTS AND DISCUSSION}

Using forest management as a tool to mitigate wildfire risk has a long history. However, issues related to fuel build-up as a consequence of fire suppression have also been identified (Johnson et al., 2002). The approach discussed here is to modify the fire regime in foresturban interface areas by reducing the fuel load, therefore potentially reducing fire intensity and preventing or at least slowing down fire spread. For example, the FireSmart guidelines (Partners in Protection 2003) provide a detailed set of rules to protect homes and properties. These rules clearly show the importance of reducing the amount of woody biomass in proximity to buildings. They also recognize the potential for different levels of management intensity. For example, the closer the trees are to buildings, the less woody biomass should 
be left on site and the lower the stand density (number of trees per hectare). If only low fire risk is acceptable (i.e., low likelihood of having a fire in the near future), then intensive management would remove most of the standing conifer trees, snags, and logs and other woody biomass on the ground. The few trees left standing should be pruned to avoid ladder fires.

The required degree of management effort depends on two main variables: a decision by the community on the level of fire risk considered acceptable in the interface area, and the local characteristics of the forest in the vicinity of the community. In addition, the size of the interface (or in other words, the area under active management for wildfire risk abatement) depends on the forest distribution, accessibility, land ownership, interests, and capabilities of each community. An important feature of these safety guidelines, however, is that all the woody biomass generated during these activities should be removed from the site to effectively reduce forest fuel loads. Traditionally, this biomass has not had commercial value, and therefore it has been burned in piles, with the consequent production of smoke and loss of biomass as potential fuel.

We simulated the Partners in Protection (2003) FireSmart guidelines in which the first 10 years of the management plan were dedicated to reducing stand density in the fire-prone areas. To avoid problems of excessive windthrow losses among the remaining trees following a sudden reduction of stand density, thinning operations were designed in two steps where $50 \%$ of harvestable trees were removed per step, and each step separated by 10 years. As a consequence, during the first 10 years of management a large amount of woody biomass was generated (Figures 5 to 7 ). We assumed that these amounts are mostly large merchantable stems, which would be more suitable for sawmill products rather than for bioenergy generation. As a consequence, none of the material generated in the initial thinning operations was used and was not included in further economic analysis. The economic sustainability analysis was therefore conducted using the annualized woody biomass generated from removing conifer regrowth only after the first 10 years, or in other words, woody understory and small trees up to 10 years old that may have grown since the initial thinning operations or later in between consecutive regrowth control operations. Discounting the areas not available for long-term management, annual woody biomass generated in a $25-\mathrm{km}$ radius around the communities was estimated at 88,486 to $100,073 \mathrm{Mg}$ biomass in Sicamous, 29,687 to $38,421 \mathrm{Mg}$ biomass in Invermere, and 14,553 to $19,619 \mathrm{Mg}$ biomass in Burns Lake. The ranges are a consequence of the maximum and minimum stand densities after preventive thinning, respectively (Figures 5 to 7 ). In energy terms, this woody

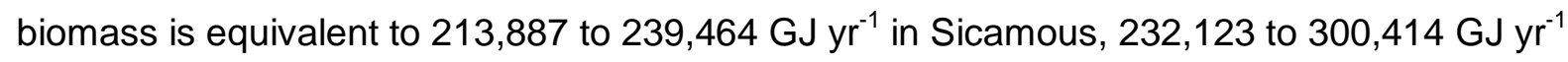


in Invermere, and 231,242 to 270,442 GJ $\mathrm{yr}^{-1}$ in Burns Lake. Harvesting that woody biomass would require 25-67 full-time-equivalent jobs.

The levelised cost of energy is estimated to range from $\$ 13-18 \mathrm{GJ}^{-1}$, which includes a $5 \%$ discount rate, 25 year utilisation period, a cost for biomass ranging from $\$ 50-75 \mathrm{Mg}^{-1}$ biomass (at $45 \%$ moisture content - wet basis), and a range of fuels for satisfying peak demand. This compares very favourably against conventional alternatives, particularly for communities without access to natural gas. These communities typically experience conventional energy prices in the range of $\$ 19-35 \mathrm{GJ}^{-1}$ before including the capital or maintenance cost of equipment (Table 1). Energy used from the woody biomass district energy system is estimated to be $78-99 \%$ less greenhouse gas intensive than the energy mix currently being used, depending on the mix of energy sources in communities and the energy sources used for satisfying peak demand in the district energy system. This analysis illustrates the economic viability of combining wildfire risk reduction and heating production, and is in clear contrast with forest plantations grown for woody biomass production, which are typically not viable without subsidies (El Kasmioui and Ceulemans, 2012).

One uncertainty in our analysis was that we were unable to obtain data to accurately model woody biomass extraction costs, which are highly variable depending on availability of labour, equipment and roads, and on forest age, site quality and dominant tree species (MacDonald 2006). In some cases, these costs might be significant. This situation is common in woody biomass feasibility studies and it indicates an area for further investigation. In our case, we think that using similar extraction costs for all the pilot communities allows us to illustrate and compare how the tool works, but advanced user should modify this value in the tool accordingly to their locally-estimated costs. Similarly, there is an urgent need for more operational field data to enable an accurate assessment of the economics of growing biomass plantations (MacDonald 2006). Most studies extrapolate and simulate data from only a relatively few studies that present their original data (EI Kasmioui and Ceulemans, 2012).

Our scenarios showed that implementing different levels of stand density control may not produce large differences in biomass production in the regrowth period (years 11-50; Figures 5 to 7 ) but could have important ecological consequences. In the intermediate and intense management scenarios, long-term woody biomass production is predicted to decline because woody biomass removal depletes nutrients from the site thereby reducing site quality and tree productivity. This phenomenon is more pronounced in areas with slower growth rates, such as the Invermere area and especially in the sub-boreal forests surrounding Burns Lake. However, even the most productive sites such as Sicamous could 
be affected. For example, at this site implementing the intensive harvesting scenario caused a predicted average decline of $22.2 \%$ in soil organic matter (Figure 8 ), which could lead to permanent site fertility losses (Seely et al., 2010; Blanco, 2012). On the other hand, implementing the minimum FireSmart guidelines might still reduce soil organic matter by $11.8 \%$ after 50 years.

If management in the forest with the most sensitive soils exceeds 50 years, there is a possibility that the loss of fertility may be irreversible. In these cases, intensive thinning should be avoided and left unmanaged after the life span of the district system ends, to allow forests to replenish their nutrient reservoirs (Blanco, 2012). The relatively small differences in woody biomass production between intensive and low management (corresponding to the maximum and minimum stand densities recommended by the FireSmart guidelines) indicate that the environmentally safest way to proceed is to apply minimal management and reserve intensive interventions for areas in close contact with buildings. Intensive treatments close to structures would also reduce transportation costs by providing feedstock from treatment units close to the district heating plant, rather than from distant forests. Fixed costs for equipment move in and move out and variable costs related to ground slope might also be reduced close to buildings and population centres.

We consider FIRST Heat a potential successful for its use at community level given a very positive reaction in the pilot communities where the tool was presented. Community planners, forest managers, wildfire risk officials, and funding agencies have found this initiative very helpful as the basis for a dialogue on the feasibility of implementing biomass district heating systems linked to sustainable forest management. The economic development and wildfire mitigation aspects of the project approach were perceived as socially positive, and the inclusion of the ecological perspective allowed for environmentrelated conversations on the suitability of implementing such heating systems.

\section{CONCLUSIONS}

The energy that could be supplied by district energy systems will vary among communities. The proportion of total energy demand will depend on the business case for the proposed district energy system, and is linked to many factors such as the heat demand density, current energy cost, etc. In one scenario, buildings connected to the new district energy system become mostly independent of fossil fuels (apart from the energy required for district energy system peaking or backup). Buildings not connected to the district energy system would continue using traditional fuels. A second scenario is that once the fuel delivery/supply is established and understood, other buildings not suitable for connection to the district 
energy system because they are too far away and therefore too expensive to connect would implement their own standalone woody biomass heating systems.

Our analysis has shown that linking geographical, ecological, financial, and energy models is valuable in producing estimations of the potential woody biomass available for bioenergy production within the context of sustainable forest management. It is possible to satisfy multiobjective management goals by linking a reduction in wildfire risk and energy production in an ecologically sustainable way, provided the ecological conditions underlying forest productivity and health are understood. At this point, FIRST Heat represents a proof of concept for a woody biomass district heat project, and does not replace a rigorous and appropriate examination/feasibility/design process specific for the target community.

\section{ACKNOWLEDGEMETS}

The authors are sincerely thankful to the help and support provided by the three pilot communities at every stage of the project. We also want to thank Alex Adams for his efforts during the early stages of the project that contributed to the takeoff of the ideas introduced here. Last but not least, we thank the Pacific Institute for Climate Solutions (PICS) for their financial support through the Carbon Management in BC Call for Applied Research. The activities reported here have been funded through the project "Community Fire Interface Biomass Utilization For Heating Fuel". Comments from anonymous reviewers helped to greatly improve the first version of this paper.

\section{SUPPLEMENTARY FILES}

In the online version of the manuscript readers can download the "supplementary information" file with detailed data on FORECAST description, calibration and evaluation processes. Also, the latest version of the FIRST Heat tool (in Microsoft Excel format) is available for free download.

\section{REFERENCES}

B.C: Hydro. 2002. Green energy study for Britisch Columbia Phase 2: Mainland. BC Hydro Green \& Alternative Enrgy Division. Report No E44. Vancouver, BC.

Bi, J., Blanco, J.A., Kimmins, J.P., Ding, Y., Seely, B., Welham, C. 2007. Yield decline in Chinese Fir plantations: A simulation investigation with implications for model complexity. Can. J. For. Res. 37, 1615-1630.

Blanco, J.A., 2012. Forests may need centuries to recover their original productivity after continuous intensive management: an example from Douglas-fir. Sci. Tot. Environ. 437, 91-103. 
Blanco, J.A., Imbert, J.B., Castillo, F.J., 2006. Influence of site characteristics and thinning intensity on litterfall production in two Pinus sylvestris L. forests in the Western Pyrenees. For. Ecol. Manage. 237, 342-352.

Blanco, J.A. Imbert, J.B., Castillo, F.J., 2008. Nutrient return via litterfall in two contrasting Pinus sylvestris forests in the Pyrenees under different thinning intensities. For. Ecol. Manage. 256, 1840-1852.

Blanco, J.A., Imbert, J.B., Castillo, F.J., 2011. Thinning affects Pinus sylvestris needle decomposition rates and chemistry differently depending on site conditions. Biogeochem. 106, 397-414.

Blanco, J.A., Seely, B., Welham, C., Kimmins, J.P., Seebacher, T.M. 2007. Testing the performance of FORECAST, a forest ecosystem model, against 29 years of field data in a Pseudotsuga menziesii plantation. Can. J. For. Res. 37, 1808-1820.

Branker, K., Pathak, M.J.M., Pearce, J.M. 2011. A review of solar photovoltaic levelised cost of electricity. Renewable Sust. Energy Reviews 15, 4470-4482.

Claveau, Y., Messier, C., Comeau, P.G., Coates, K.D. 2002. Growth and crown morphological responses of boreal conifer seedlings and saplings with contrasting shade tolerance to a gradient of light and height. Can. J. For. Res. 32, 458-468.

Cokcing, M.I., Varner, J.M., Sherriff, R.L., 2012. California black oak responses to fire severity and native conifer encroachment in the Klamath Mountains. For. Ecol. Manage. 270, 25-34.

Comeau, P.G., Heineman, J.L. 2003. Predicting understory light microclimate from stand parameters in young paper birch (Betula papyrifera Marsh) stands. For. Ecol. Manage. 180, 303-315.

Darling, S.B., You, F., Veselka, T., Velosa, A. 2011. Assumptions and the levelised cost of energy for photovoltaics. Energy Environ. Sci. 4, 3133-3139.

Dubois, D., Littlejohn, D., Robinson, P., Blanco, J.A., Flanders, D., 2012. District Heating: A Tool to Protect Communities from Wildfire While Reducing Green House Gases. International Symposium on Sustainability, 62nd Canadian Chemical Engineering Conference, Vancouver, BC. 14-17 October.

El Kasmioui, O., Ceulemans, R. 2012. Financial analysis of the cultivation of poplar and willow for bioenergy. Biom. Bienerg. 43, 52-64.

ENVINT Consulting, 2011. An Information Guide on Pursuing Biomass Energy Opportunities and Technologies in British Columbia. Prepared for BC Biomass Network, Vancouver, BC

European Union Commission. 2010. Report from the Commission to the Council and the European Parliament on sustainability requirements for the use of solid and gaseous biomass sources in electricity, heating and cooling. SEC(2010) 65, SEC(2010) 66. Brussels.

Flanders, D., Sheppard, S.R.J., Blanco, J.A., 2009. The Potential for Local Bioenergy in Low-Carbon Community Planning. Smart Growth on the ground: Prince George. Foundation research Bullletin \#4. Smart growth BC, Vancouver, BC.

Green Heat Initiative., 2010. A renovable biomass energy vision for 2025. Quesnel, BC.

Ghafghazi, S. 2011. Multi criteria evaluation of wood pellet utilization in district heating systems. PhD Thesis, The University of British Columbia, Vancouver BC.

de Groot, W.J., Flanningan, M.D., Cantin, A.S., 2012. Climate change impacts of future boreal fire regimes. Forest Ecology and Management, in press. doi.org/10.1016/j.foreco.2012.09.027. 
Hirsch, K.G., Fuglem, P. (Eds.) 2006. Canadian wildland fire strategy: background syntheses, analyses, and perspectives. Canadian Council of Forest Ministers, Nat. Res. Canada, Can. For. Ser., Nort. For. Cen., Edmonton, AB.

IPCC, 2011. Special report on renewable energy sources and climate change mitigation. Prepared by working group III of the Intergovernmental Panel on Climate Change.Cambridge University Press, Cambridge and New York.

Jolly, W.M., Parsons, R., Varner, J.M., Butler, B.W., Ryan, K.C., Gucker, C.L. 2012. O mountain pine beetle outbreaks change the probability of active crown fire in lodgepole pine forests? Comment. Ecology 93, 941-946.

Johnson, E.A., Miyanishi, K., Bridge, S.R.J. 2001. Wildfire regime in the boreal forest and the iea of fires supresison and fuel builup.. Cons. Biol. 15, 1554-1557.

Keeley, J.E., Fotheringham, C.J., Morais, M. 1999. Reexamining fire suppression Impacts of brushland fire regimes. Science 284, 1829-1832.

Kimmins, J.P., 2004. Forest Ecology: a foundation for sustainable forest management and environmental ethics in forestry, 3rd Edit. Prentice Hall, Upper Saddle River, NJ.

Kimmins, J.P, Catanzario, J.D., Binkley, D 1979. Tabular summary of data from the literature on the biogeochemistry of temperate forest ecosystems. ENFOR Project P-8. Natural Resources Canada. Vancouver, BC.

Kimmins, J.P., Mailly, D., Seely, B., 1999. Modelling forest ecosystem net primary production: the hybrid simulation approach used in FORECAST. Ecol. Model. 122, 195-224.

Kimmins, J.P., Blanco, J.A., Seely, B., Welham, C., Scoullar, K., 2010. Forecasting Forest Futures: A Hybrid Modelling Approach to the Assessment of Sustainability of Forest Ecosystems and their Values. Earthscan Ltd. London, UK.

Leifers, V. J., Pinno, B.D., Stadt, K.J. 2002. Light dynamics and free-to-grow standards in aspen dominated mixedwood forests. For. Chron. 78: 137-145.

Li, Z., Kurz, W.A., Apps, M.J., Beukema, S.J. 2003. Belowground biomass dynamics in the Carbon Budget Model of the Canadian Forest Sector: recent improvements and implications for the estimation of NPP and NEP. Can. J. For. Res. 33: 126-136.

Mailly, D.,Kimmins, J.P. 1997. Growth of Pseudotsuga menziesii and Tsuga heterophylla seedlings along a light gradient: resource allocation and morphological acclimation. Can. J. Bot. 75, 14241435.

MacDonald, A.J. 2006. Estimated costs for harvesting, comminuting, and Transporting beetle-killed pine in the Quesnel/Nazlo area of Central British Columbia. FERIC Advantage Report 7(16), Vancouver, BC.

Messier, C., Parent, S., Bergeron, Y. 1998. Effects of Overstory vegetation on the understory light environment in mixed boreal forests. J. Veg. Sci. 9, 511-520.

National Energy Board of Canada. 2011. Energy Facts. Las accessed March $20^{\text {th }}$ 2015. Available at: http://www.neb-one.gc.ca/nrg/ntgrtd/mrkt/archive/2011cndnnrgprcngtrndfct/cndnnrgprengtrndfcteng.pdf.

Natural Resources Canada. 2015. Energy sources: Average retail prices for furnace oil Last accessed on March $20^{\text {th }} 2015$. Available at: 
http://www2.nrcan.gc.ca/eneene/sources/pripri/prices bycity e.cfm?PriceYear=2005\&ProductlD= 7\&LocationID $=70,5,14,4,2 \#$ PriceGraph

Partners in Protection, 2003. FireSmart: protecting your community from wildfire. Partners in Protection. Edmonton, AB.

Peterson, E.B. 1988. An ecological primer on major boreal mixedwood species. In Management and utilization of northern mixedwoods. In: Samoil, J.K. (ed). Can. For. Serv. North. For. Cent. Inf. Rep. NOR-X-296. pp. 5-12.

Peterson, E.B., and N.M. Peterson. 1992. Ecology, management, and use of aspen and balsam poplar in the prairie provinces. For. Can., Nort. For. Cen., Spec. Rep. 1., Edmonton, AB.

Prescott, C.E., Blevins, L.L., Staley, C.L.. 2000a. Effects of clearcutting on decomposition rates of litter and forest floor in forests of British Columbia. Can. J. For. Res. 30, 1751-1757.

Prescott, C.E., Zabek, L.M., Staley, C.L., Kabzems, R. 2000b. Decomposition of broadleaf and needle litter in forests of British Columbia: influences of litter type, and litter mixtures. Can. J. For. Res. 30, 1742-1750.

Pojar, J., Klinka, K., Meidinger, D.V., 1987. Biogeoclimatic ecosystem classfication in British Columbia. For. Ecol. Manage. 22, 119-154.

Renney, A. 2012. Barrier to the woody biomass energy industry in British Columbia. MSc Thesis, Queen's University, Kingston, ON.

Seely, B., C. Welham, Kimmins, J.P. 2002. Carbon Sequestration in a Boreal Forest Ecosystem: Results from the Ecosystem Simulation Model, FORECAST. For. Ecol. Manage. 169, 123-135.

Seely B., Hawkins C., Blanco J.A., Welham C., Kimmins J.P. 2008. Evaluation of a mechanistic approach to mixedwood modelling. For. Chron., 84, 181-193.

Seely, B., Welham, C., Blanco, J.A., 2010. Towards the application of soil organic matter as an indicator of ecosystem productivity: Deriving thresholds, developing monitoring systems, and evaluating practices. Ecol. Ind. 10, 999-1008.

Sevilgen, S.H., Erdem, H.H., Cetin, B., Akkaya, A.V., Dagdas A. 2005. Effect of economic parameters on power generation expansion planning. Energy Convers. Manage. 46, 180-1789.

Sheltair, 2007. City of Prince George energy and greenhouse gas management plan. Prince George, $\mathrm{BC}$.

Simpson, J., Jaccard, M., Rivers. N., 2007. Hot Air: Meeting Canada's Climate Change Challenge. McClelland \& Stewart, Toronto, ON.

Sullivan, T.P., Sullivan, D.S., Lingren, P.M.F., Ransome, D.B., Bull, J.G., Ristea, C., 2011. Bioenergy or biodiversity? Woody debris structures and maintenance of red-backed voles on clearcuts. Biom. Bioen. 35, 4390-4398.

United States Forest Service (USFS), 2008. Woody biomass utilization: what is woody biomass utilization? Accessed on March $24^{\text {th }} 2015$ from http://www.fs.fed.us/woodybiomass/whatis.shtml.

Wang, J. R., Zhong, A.L., Simard, S.W., Kimmins, J.P.. 1996. Aboveground biomass and nutrient accumulation in an age sequence of paper birch (Betual papyrifera) in the Interior Cedar Hemlock zone, British Columbia. For. Ecol. Manage. 83: 27-38.

Westerling, A.L., Hidalgo, H.G., Cayan, D.R., Swetnam, T.W., 2006. Warming and earlier spring increase western U.S. forest wildfire activity. Science 313, 940-943. 
Table 1: Energy content, price and cost of fuel types in BC. (Sources: Dubois et al. 2012; Ghafghazi 2011, BC Hydro 2002).

\begin{tabular}{lcccccc}
\hline \multicolumn{1}{c}{ Fuel Type } & Unit Sale & Energy Content & Retail Price & \multicolumn{2}{c}{ Typical cost in BC } & LCOE \\
& & GJ / Unit Sale & \$ / Unit Sale & \$/GJ & \$ / MWh & \\
\hline Natural Gas & GJ & 1.0 & $11-19$ & $11-19$ & $40-70$ & $55-85$ \\
Propane & Litres & 0.0253 & $0.48-0.63$ & $19-25$ & $70-90$ & $115-140$ \\
Electricity & kWh & 0.0036 & $0.068-0.083$ & $19-23$ & $70-80$ & $30-100$ \\
Heating Oil & Litres & 0.0387 & $0.74-0.97$ & $19-25$ & $70-90$ & N/A \\
Ponderosa Pine & Cord & 17.9 & $200-250$ & $11-14$ & $40-60$ & $55-187$ \\
Wood Chips & Green Tonne & 11.2 & $35-55$ & $3-5$ & $10-20$ & $55-187$ \\
Pellets (Retail) & Tonne & 19.2 & $175-210$ & $9-11$ & $30-40$ & $55-65$ \\
\hline
\end{tabular}


Table 2. Parameters used in the study cases (same values for the three sites). All heating network assumptions are illustrative and not configured to specific buildings in any of the communities. For ease of comparison only, identical assumptions were made for each of the three communities. For specific community applications, assumptions tailored to each community must be made in the "Assumptions" page of the FIRST Heat tool. Data elaborated upon IPCC (2011), ENVIT (2011), and our own databases from CEA and WW2RH.

\begin{tabular}{|c|c|c|}
\hline Biomass available & Value & Observations \\
\hline Non-harvestable Material & $0 \%$ & \\
\hline Harvested material not available at roadside & $15 \%$ & \\
\hline Harvested material left at roadside & $15 \%$ & \\
\hline Biomass fuel sent to plant & $70 \%$ & \\
\hline Energy content of wood & 20.32 & GJ / oven-dry $10^{3} \mathrm{~kg}$ \\
\hline Biomass moisture content & $45 \%$ & Wet basis \\
\hline Higher Heating Value & 11.17 & GJ $/ 10^{3} \mathrm{~kg}$ \\
\hline \multicolumn{3}{|l|}{ District energy system analysis } \\
\hline Interest/discount rate & $5.0 \%$ & \\
\hline Operational life & 50 & years \\
\hline Investment return period & 25 & years \\
\hline Operational Hours at full Load & 4,000 & hours / year \\
\hline Biomass plant efficiency & $85 \%$ & \\
\hline Peaking plant efficiency & $85 \%$ & propane \\
\hline Total district energy system efficiency & $75 \%$ & \\
\hline Total district energy system output from biomass & $90 \%$ & \\
\hline Cost of commercial buildings & $\$ 3,767$ & $/ \mathrm{m}^{2} \quad\left(\$ 350 / \mathrm{ft}^{2}\right)$ \\
\hline Area of boiler house & 92.91 & $\mathrm{~m}^{2}\left(1000 \mathrm{ft}^{2}\right)$ \\
\hline District energy grid length & 700 & $\mathrm{~m}$ \\
\hline Cost of trenching & $\$ 500$ & $\$ / \mathrm{m}$ \\
\hline Additional cost for district heating pipe & $\$ 200$ & $\mathrm{~m}$ \\
\hline \multicolumn{3}{|l|}{ Labour } \\
\hline Estimated jobs from DE system construction phase & 6.220 & jobs $/ \$ 1,000,000$ capital \\
\hline$\%$ biomass mechanical fall \& removal & $80 \%$ & \\
\hline$\%$ biomass hand fall \& removal & $20 \%$ & \\
\hline People power required for mechanical fall \& removal & 0.12114 & person days $/ 10^{3} \mathrm{~kg}$ \\
\hline People power required for hand fall \& removal & 1.60658 & person days $/ 10^{3} \mathrm{~kg}$ \\
\hline \multicolumn{3}{|l|}{ Energy costs } \\
\hline Natural Gas & $\$ 10.00$ & $\$ / G J$ \\
\hline Electricity & $\$ 0.075$ & $\$ / k W h$ \\
\hline Propane & $\$ 0.49$ & $\$ / L$ \\
\hline Heating Oil & $\$ 1.20$ & $\$ / L$ \\
\hline Biomass $^{\mathrm{a}}$ & $\$ 50.00-\$ 75.00$ & $\$ /$ oven-dry $10^{3} \mathrm{~kg}$ \\
\hline Natural Gas & $\$ 10.00$ & $\$ / G J$ \\
\hline
\end{tabular}

${ }^{a}$ Biomass costs include extraction, handling and transport costs (MacDonald 2006). 


\section{Figure legends}

Figure 1. BC's biogeoclimatic zones (sensu Pojar et al. 1987). Also shown, are the locations of the three communities used for the pilot projects, Burns Lake, Sicamous, and Invermere.

Figure 2. Steps taken to create the FIRST Heat tool. First, geo-referenced data on forest types, wildfire risk, land ownership, and local management plants are used to create for each community a GIS map with different polygons, each representing one forest stand. Then, stands with the same ecological attributes are grouped in stand types, and their evolution through time under different management regimes simulated with FORECAST. The result library of ecosystem-level attributes (biomass, SOM: soil organic matter, etc) is linked to a set of equations defining the energy and financial models. The result is the FIRST Heat tool.

Figure 3. FORECAST is the forest-growth engine of FIRST Heat. The model simulates tree growth based on potential biomass generated by the foliage through photosynthesis (central circle).

Photosynthesis depends on the efficiency of leaf nitrogen, which is limited by the availability of light and nutrients. Nutrients in the ecosystem can be in different compartments (rectangles), and transfer between them following natural or anthropogenic pathways (diamonds) (modified from Kimmins et al. 1999).

Figure 4. User interface for the screening tool FIRST Heat. In the upper-left corner the user selects the ecological conditions and the size of the forest - urban interface of the target community. In the bottomleft corner the user inputs the parameters defining the community profile (optional) and the proposed district heating system. Biomass, energy, jobs, costs and GHG produced are provided in the right half of the screen.

Figure 5. Forest biomass projections (in $\mathrm{Mg} \mathrm{yr}^{-1}$ ) for Burns Lake under three different management regimes (Min.: less intensive intervention, highest stand density and long regrowth control cycle; Int: intermediate intervention, lowest stand density and longest regrowth control cycle; Max: more intensive intervention, lowest stand density and short regrowth control cycle); and three land uses under forest operations (see description under Study Area).

Figure 6. Forest biomass projections for Invermere under three different management regimes (Min.: less intensive intervention, highest stand density and long regrowth control cycle; Int: intermediate intervention, lowest stand density and longest regrowth control cycle; Max: more intensive intervention, lowest stand density and short regrowth control cycle); and three land uses under forest operations (see description under Study Area).

Figure 7. Forest biomass projections for Sicamous under three different management regimes (Min.: less intensive intervention, highest stand density and long regrowth control cycle; Int: intermediate intervention, lowest stand density and longest regrowth control cycle; Max: more intensive intervention, lowest stand density and short regrowth control cycle); and three land uses under forest operations (see description under Study Area).

Figure 8. Relative change in soil organic matter (SOM) content in two mixed conifer forests (Douglasfir, western redcedar, and western hemlock) in Sicamous: a young forest in a medium quality site (upper panel); and a mature forest in a poor quality site (lower panel). Different management control plans for three different levels of wildfire risk corresponding to maximum, intermediate and minimum interventions as recommended by FireSmart. Stand types correspond to $\mathrm{Fd} \mathrm{Cw} \mathrm{Hw}$ medium and $\mathrm{Hw}$ Cw Fd poor in Table S3 (supplementary material). 


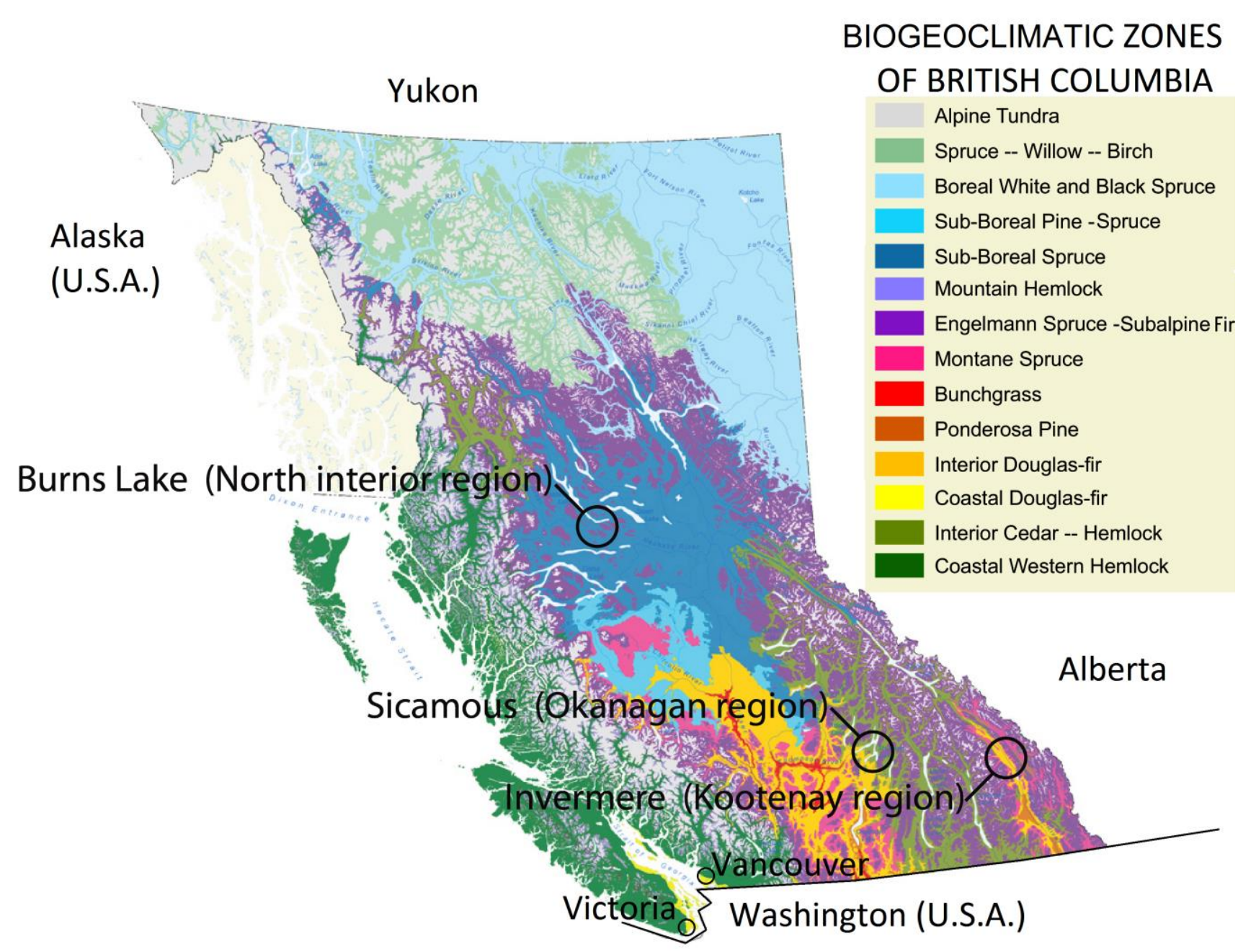

Figure 1. 
Geographical model

FORECAST

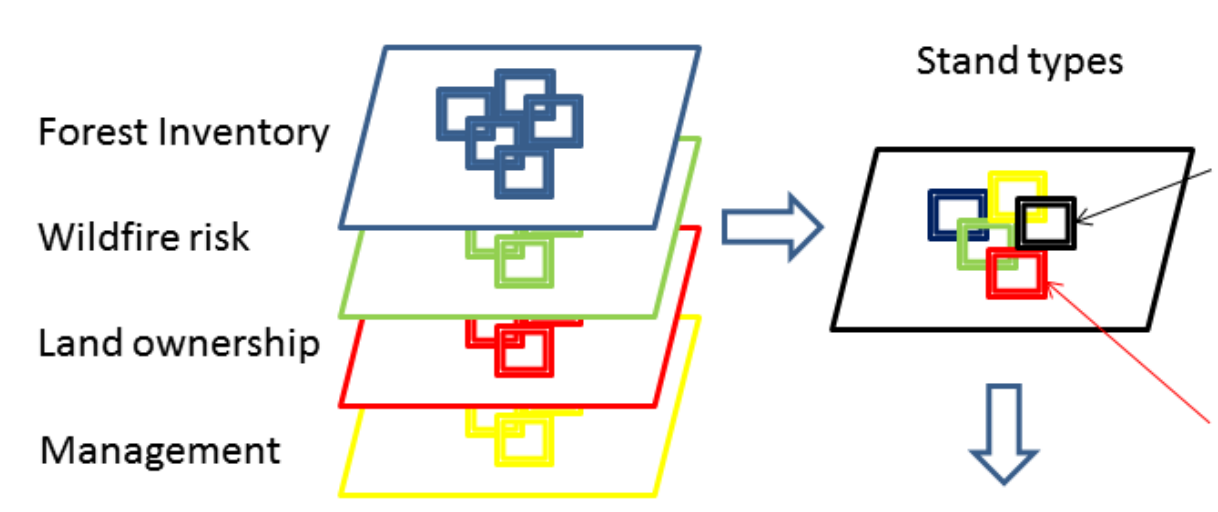

Ecological model

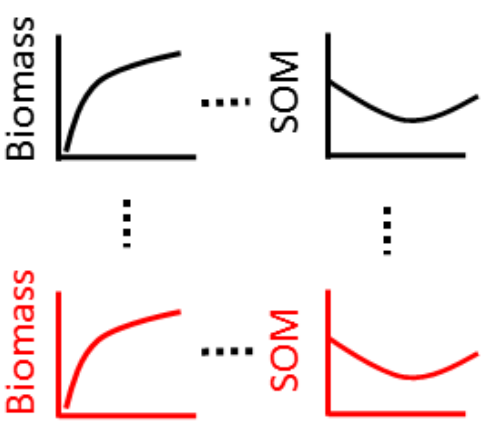

Library

Stand age

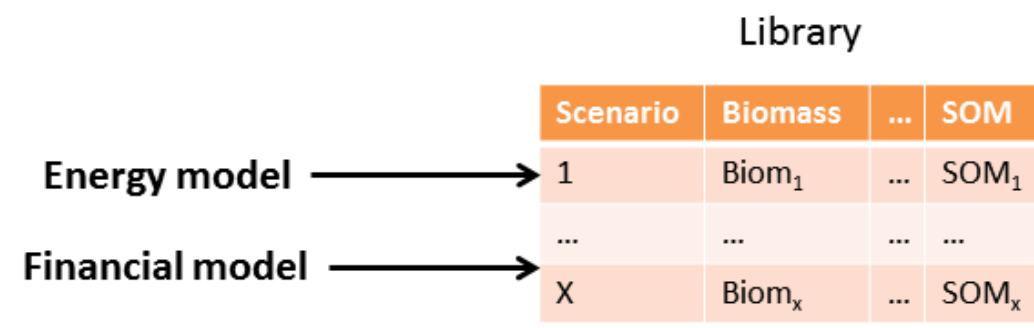

FIRST Heat

Figure 2. 


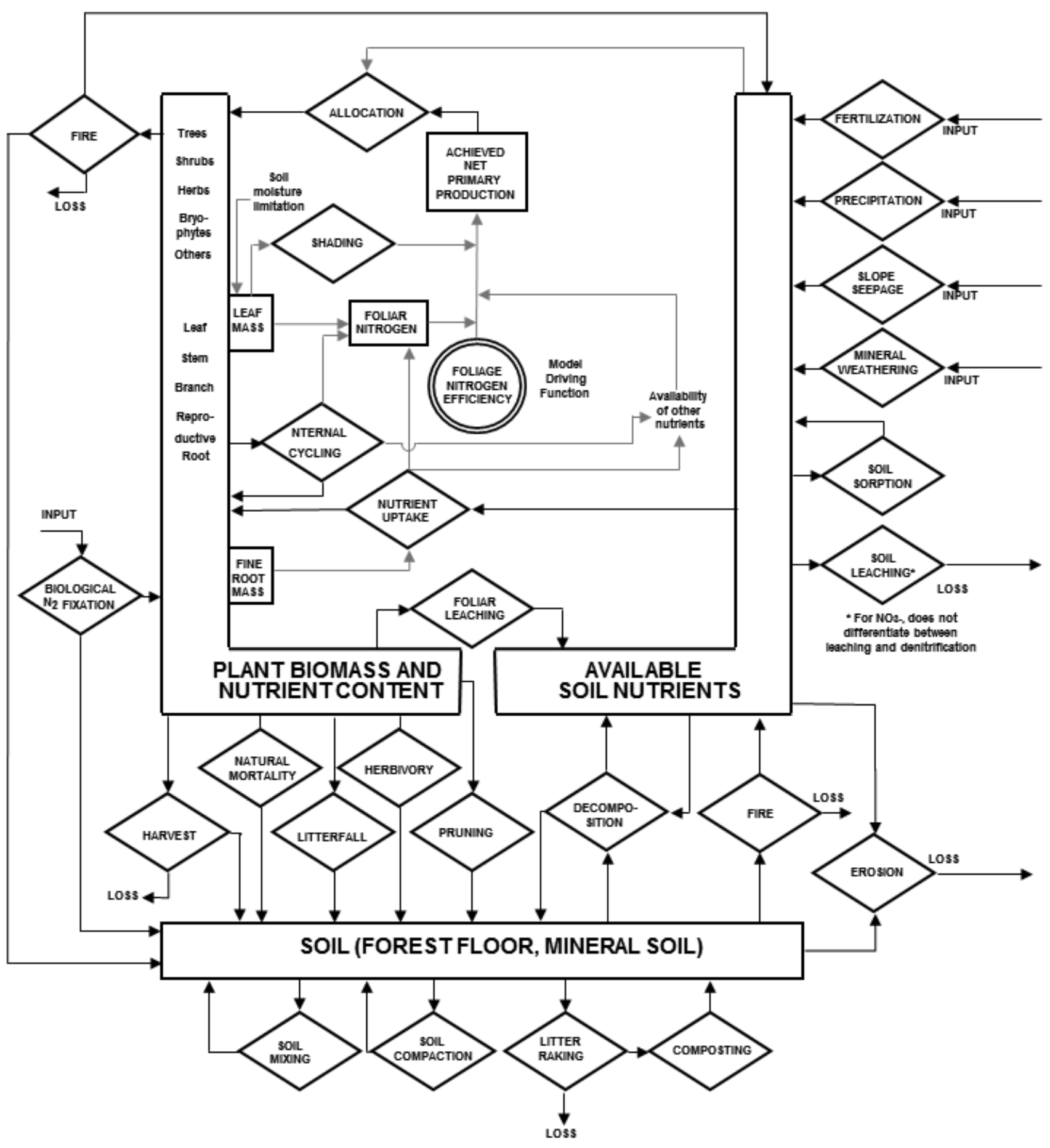

Figure 3. 
This prefeasibility tool is intended to provide a community with an initial understandine, providing direction for the next phase of investigation. 2 Note: all units in metric. All calculations are estimates.

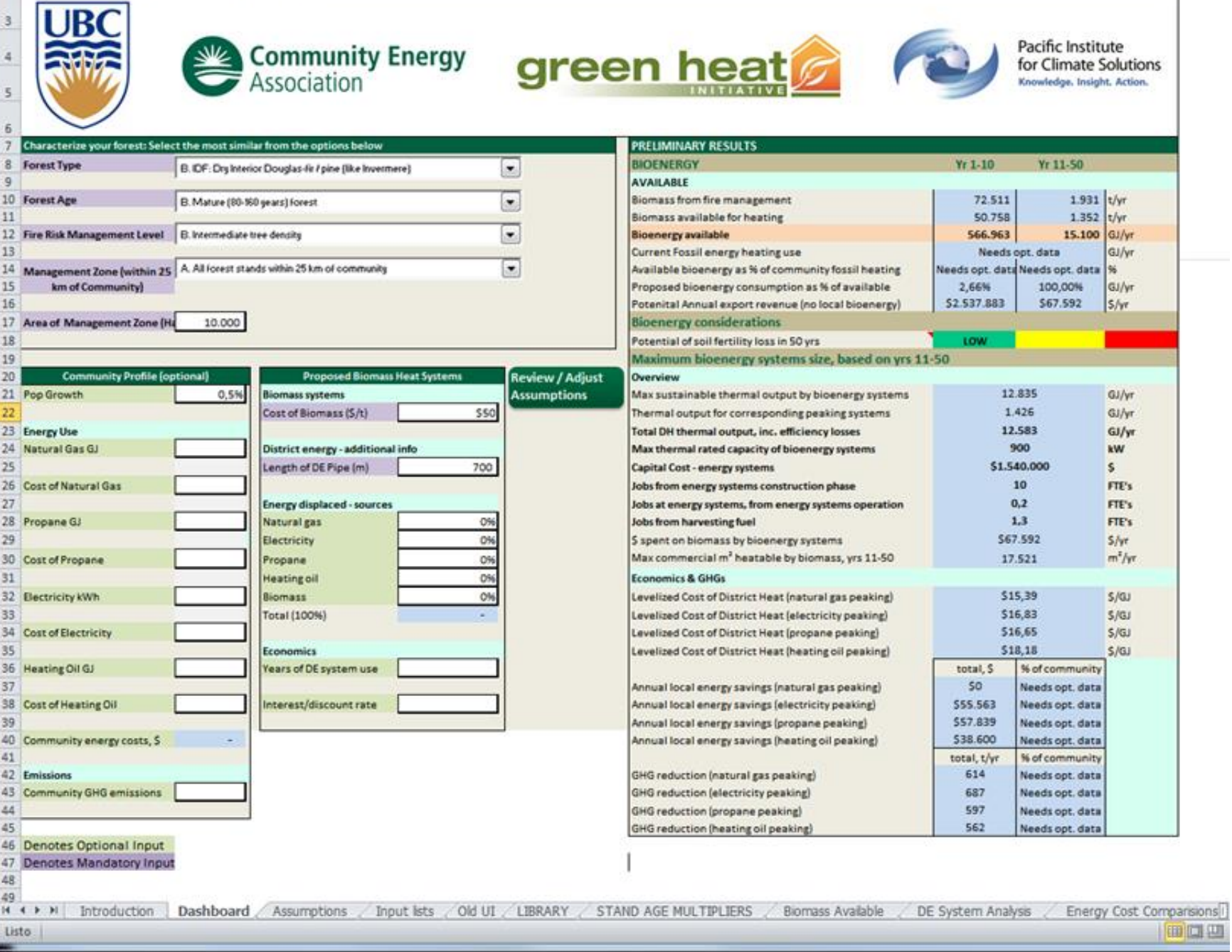

Figure 4. 
Burns Lake: Harvested biomass available annually from years 1-11 (intermediate mgmt scenario)

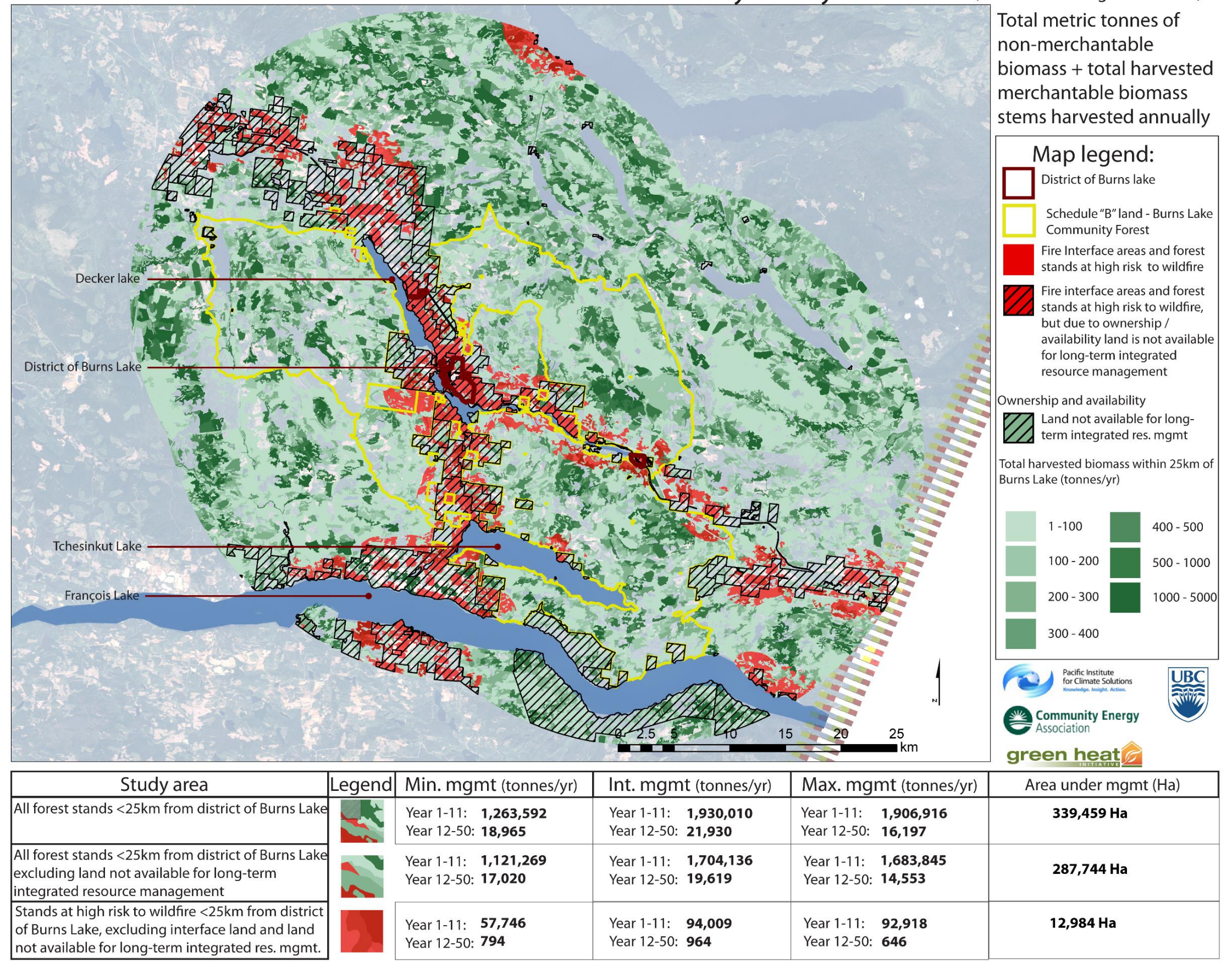

Figure 5 
Invermere: Harvested biomass available annually from years 1-11 (intermediate mgmt scenario)

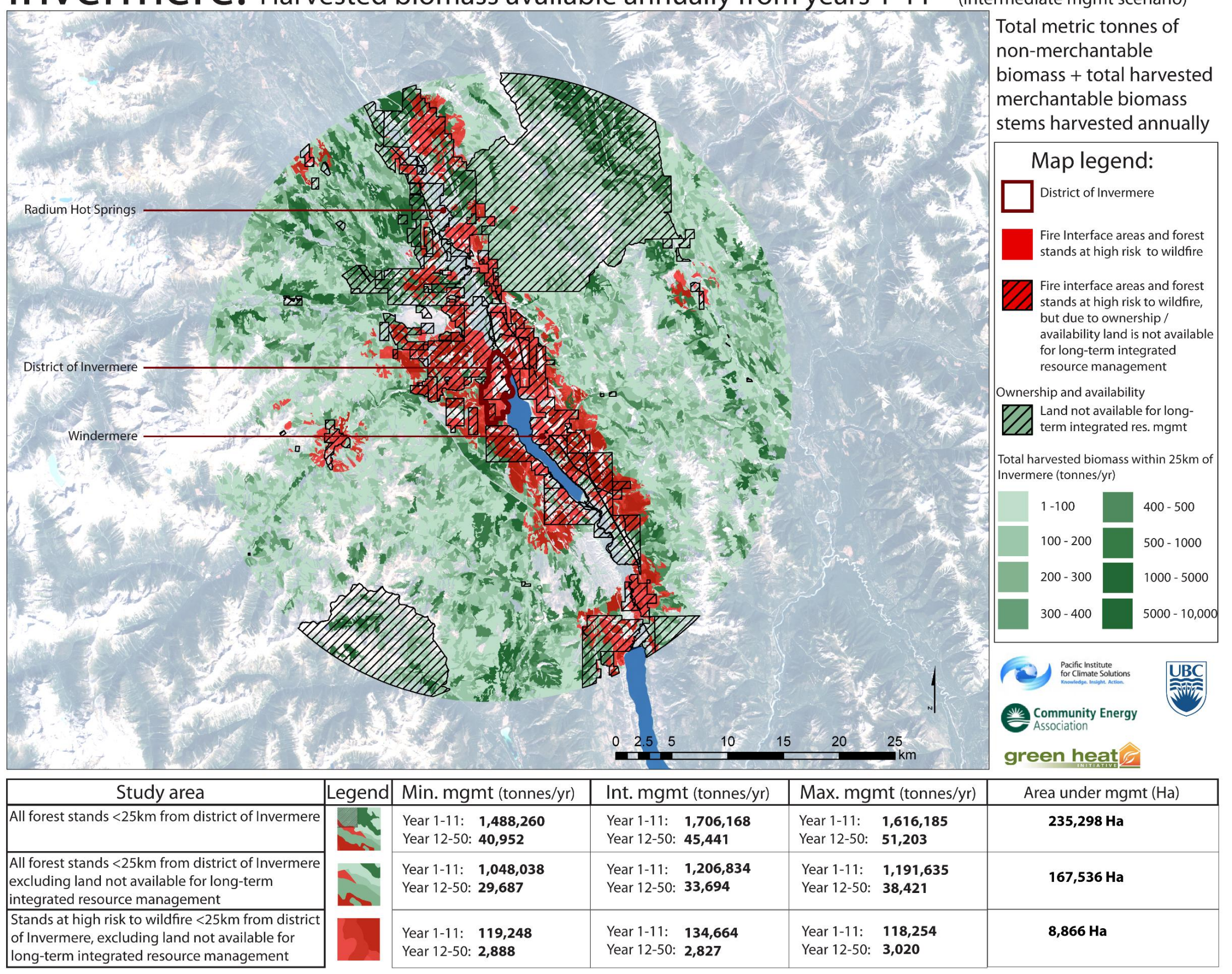


Sicamous: Harvested biomass available annually from years 1-11 (intermediate mgmt scenario)

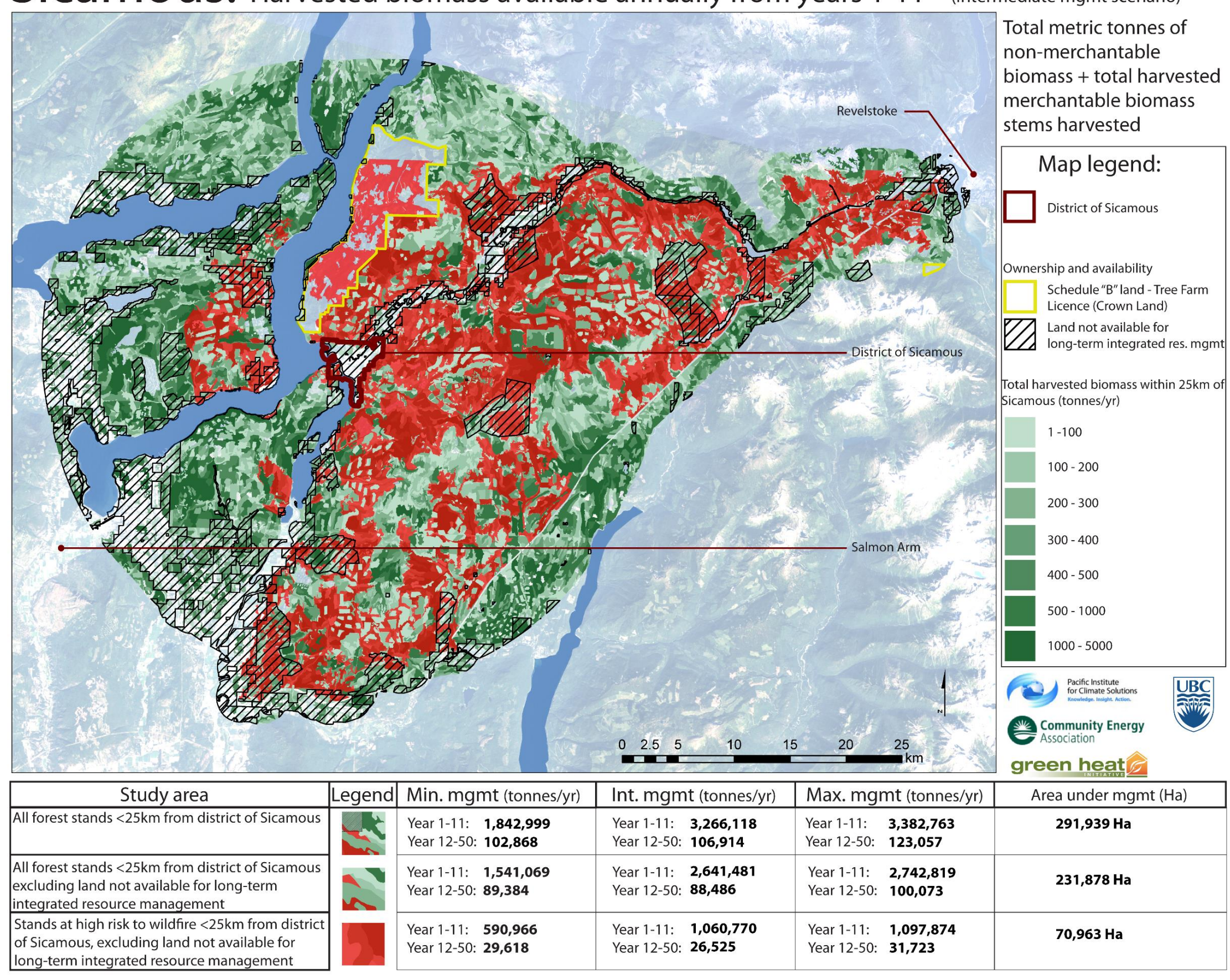




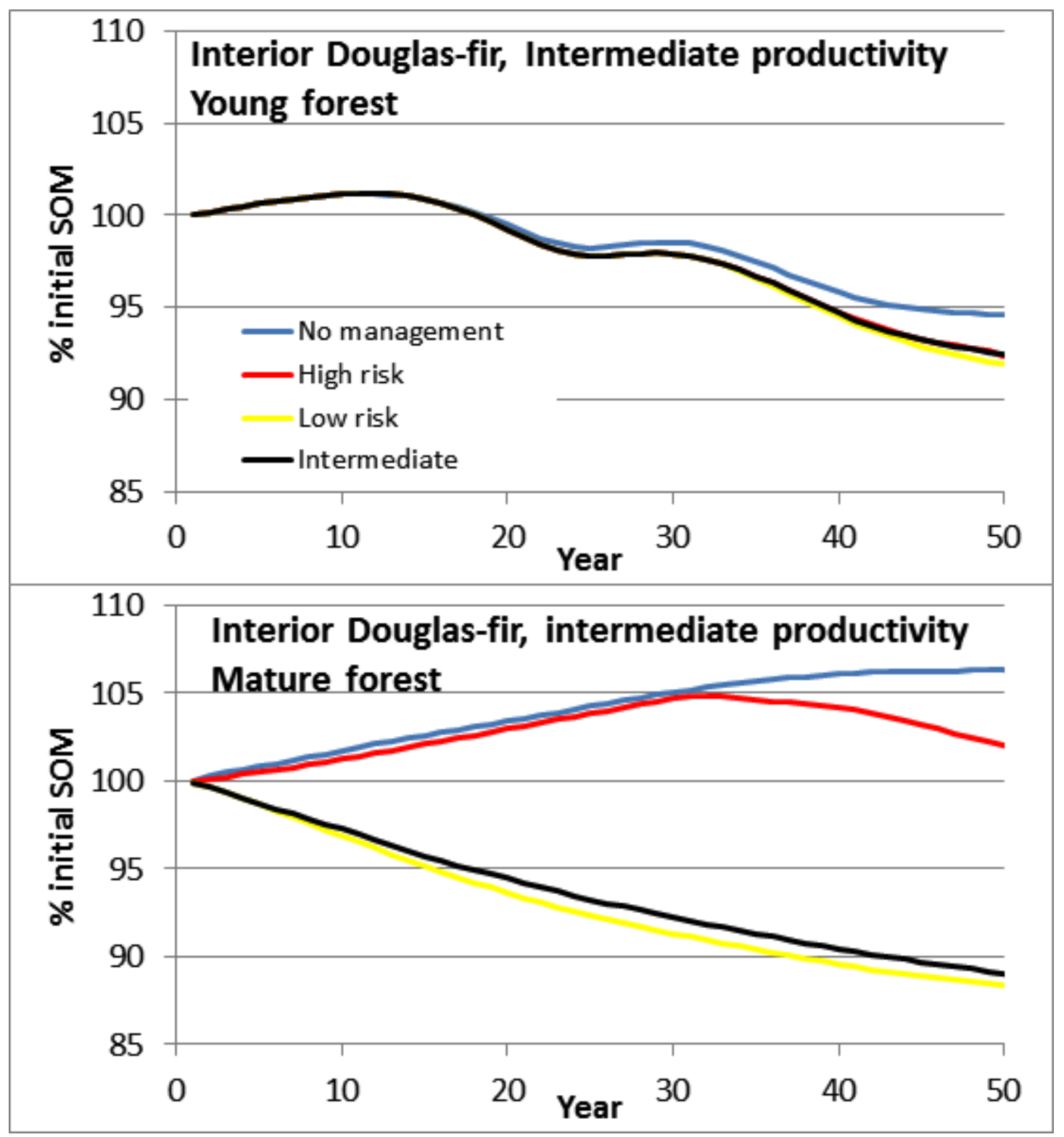

Figure 8

This work is licensed under the Creative Commons Attribution-NonCommercial-NoDerivatives 4.0 International License. To view a copy of this license, visit http://creativecommons.org/licenses/by-nc-nd/4.0/ or send a letter to Creative Commons, PO Box 1866, Mountain View, CA 94042, USA. 